\title{
Gene polymorphism and plasma levels of miR-155 in diabetic retinopathy
}

\author{
E R Polina', F M Oliveira', R C Sbruzzi' ${ }^{1}$, Crispim², L H Canani ${ }^{2,3}$ and K G Santos ${ }^{1,4}$ \\ ${ }^{1}$ Laboratory of Human Molecular Genetics, Universidade Luterana do Brasil (ULBRA), Canoas, Brazil \\ 2Endocrine Division, Hospital de Clínicas de Porto Alegre (HCPA), Porto Alegre, Brazil \\ ${ }^{3}$ Department of Internal Medicine, Universidade Federal do Rio Grande do Sul (UFRGS), Porto Alegre, Brazil \\ ${ }^{4}$ Cardiovascular Research Laboratory, Hospital de Clínicas de Porto Alegre (HCPA), Porto Alegre, Brazil
}

Correspondence should be addressed to K G Santos: katia.santos@ulbra.br

\begin{abstract}
Circulating microRNA-155 (miR-155) is associated with type 2 diabetes mellitus (T2DM) and the rs767649 polymorphism in the pre-MIR155 gene is associated with miR-155 expression. However, their relationship with diabetic retinopathy (DR) is still unknown. Therefore, the aim of this case-control study was to test the hypothesis that the rs767649 polymorphism in the pre-MIR155 gene is associated with DR in South Brazilians with T2DM. We also evaluated the association of plasma levels of miR-155 with DR and the rs767649 polymorphism in a subgroup of subjects. The rs767649 polymorphism was genotyped in 139 blood donors and 546 T2DM patients (244 had no DR, 161 had non-proliferative DR and 141 had proliferative DR). miR-155 expression was quantified in 20 blood donors and 60 T2DM patients (20 from each group). Among T2DM patients, the carriership of the $A$ allele and the $A$ allele were more frequent in subjects with $D R$ than in those without it $(P<0.05)$, and the $A$ allele was independently associated with an increased risk of DR (adjusted $\mathrm{OR}=2.12,95 \% \mathrm{Cl}=1.12-4.01$ ). . The plasma levels of miR-155 were lower in T2DM patients than in blood donors $(P<0.001)$. However, the miR-155 levels did not differ according to the presence and severity of DR or according to rs767649 genotypes among T2DM patients. These findings support that the rs767649 polymorphism in the pre-MIR155 gene is associated with DR in T2DM and that the miR-155 plasma levels might be associated with T2DM. Additional studies are needed to further investigate their clinical significance in DR and T2DM.
\end{abstract}
Key Words
- type 2 diabetes
- diabetic retinopathy
- miR-155
- polymorphism
- gene expression
- plasma

Endocrine Connections (2019) 8, 1591-1599

\section{Introduction}

Diabetic retinopathy (DR) is a neurodegenerative complication of diabetes (1) consistently associated with other diabetic complications and with an overall worse prognosis (2). Hyperglycaemia triggers the activation of biochemical pathways that induce inflammation and oxidative stress, thus leading to blood-retinal barrier breakdown, pericyte loss, neuronal death and angiogenesis (3).

miRNAs are small ncRNA molecules that regulate gene expression mainly through the induction of mRNA degradation and translational inhibition of their target mRNAs (4). miRNAs are key regulators of inflammatory responses associated with both early and late stages of DR (5) and their differential expression has been reported in cultured retinal cells, animal models of DR and patients with DR. The high stability of circulating miRNAs has highlighted their potential as non-invasive biomarkers of DR (6). In addition, sequence variation in genes encoding miRNAs could alter their biogenesis, maturation or target binding, thereby affecting disease susceptibility and progression $(7,8)$. However, to date, there are almost no studies on the association of polymorphisms in miRNA genes with DR $(9,10)$.

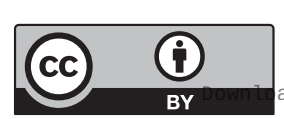

This work is licensed under a Creative Commons Attribution 4.0 International License. 
miR- 155 controls both the innate and adaptive immune systems. It is expressed in several immune cell types, where it acts a positive modulator of cell proliferation, cell differentiation and effector responses, such as cytokine and antibody production (11). miR-155 is responsive to stress, oxygen (12) and many inflammatory stimuli, such as those induced by cytokines (11). In relation to glucose metabolism and insulin signalling, miR-155 was shown to be a positive regulator of insulin sensitivity and required for normal blood glucose homeostasis (13). miR-155 is also expressed in normal murine retina and retinal endothelial cells $(14,15)$. In retina, miR-155 is highly expressed at early embryonic stages as part of a mechanism that controls the cell fate and timing of the generation of retinal bipolar cells (16). In addition, miR-155 was suggested to modulate retinal vessel growth and remodelling during postnatal development and under ischaemia (17).

Dysregulated expression of miR-155 has been associated with pathological conditions characterized by chronic inflammation (11), neurodegeneration and neovascularization (12). miR-155 expression increases during inflammatory response and miR-155 overexpression, in turn, enhances the production of inflammatory molecules (11). However, its mechanistic role in DR is still unexplored (14) and few studies have evaluated circulating levels of miR-155 in humans with DR $(18,19)$. miR-155 is generated from an exon of a long ncRNA encoded in the chromosome 21q21.3 (20). Some polymorphisms in the pre-MIR155 gene were predicted to change the secondary structure of pre-miR-155 and were shown to affect the expression and function of miR-155 in mice and humans (21). The presumably functional rs767649 polymorphism upstream of the pre-MIR155 gene was recently associated with type 1 diabetes (T1DM) (22) and type 2 diabetes (T2DM) (23). However, its possible association with DR has not yet been investigated.

Therefore, this study was designed to investigate whether the rs767649 polymorphism in the pre-MIR155 gene is associated with DR in South Brazilians with T2DM. In a subgroup of T2DM patients, we also evaluated whether the plasma levels of miR-155 are associated with DR, the rs767649 polymorphism and the clinical variables.

\section{Materials and methods}

\section{Study population and data collection}

This case-control study was carried out on 546 outpatients with T2DM and 139 presumably non-diabetic blood donors. Two hundred and ninety-eight patients were enrolled between 1999 and 2010 in the endocrinology outpatient clinics of two public tertiary care hospitals in Porto Alegre, the capital of Rio Grande do Sul State in Southern Brazil (Hospital de Clínicas de Porto Alegre - HCPA and Hospital Nossa Senhora da Conceição). The other 248 patients were enrolled between 2015 and 2017 in the endocrinology outpatient clinic of HCPA. Type 2 diabetes was defined according to the criteria of American Diabetes Association (24), and the inclusion criteria for this study were age $\geq 30$ years at the diagnosis of diabetes, no need of permanent insulin treatment during the first year after diagnosis and no previous episodes of ketoacidosis. Patients underwent a clinical evaluation consisting of physical examination and routine laboratory examinations, such as glycated haemoglobin (HbA1c), serum creatinine and lipid profile, which were determined according to standard methods as previously described in detail (25). The CKD-EPI equation was used to estimate the glomerular filtration rate (eGFR) (26) and a questionnaire was used to collect data regarding the clinical history, including age at the diagnosis of diabetes, smoking habits, use of medication and presence of comorbidities.

Diabetic retinopathy was diagnosed by ophthalmoscopy (patients enrolled until 2010) or retinal photography (patients enrolled between 2015 and 2017) with dilated pupils by staff ophthalmologists specialized in retina from each institution, who were blinded to the patients' molecular data. Subjects who had severe cataract or any other eye condition that impairs fundus examination were not included in the study. Retinopathy was graded according to the worst affected eye and was classified as absent (no abnormalities), non-proliferative (NPDR; microaneurysms, intraretinal haemorrhages, venous beading and intraretinal microvascular abnormalities) or proliferative (PDR; neovascularization or vitreous/preretinal haemorrhage) (27). Patients who had been previously treated with panretinal photocoagulation were also considered as having PDR. Patients with DR were defined as case subjects $(n=302)$ and patients without DR with a known diabetes duration of at least 5 years were defined as control subjects $(n=244)$. Among the 302 case subjects, 161 had NPDR and 141 had PDR.

In order to determine the frequency of the rs767649 polymorphism and the plasma levels of miR-155 in the general population, we also included 139 unrelated blood donors from the Haemotherapy Division of HCPA, who were enrolled between 2000 and $2001(n=67)$ or 2017 and $2018 \quad(n=72)$. A questionnaire was used to collect data regarding age, gender, skin colour/ethnicity, use of medication and diabetes-related information.

This work is licensed under a Creative Commons Attribution 4.0 International License. ded from Bioscientifica com at 04/26/2023 12:53:26PM 
Blood donors with a known personal and/or first-degree family history of diabetes were not included in the study, and no additional data were collected from them.

This study was approved by the Research Ethics Committees of HCPA and ULBRA (CAAE numbers 35065914.9.0000.5327 and 35065914.9.3001.5349, respectively), and all subjects gave written informed consent. Skin colour/ethnicity was self-declared and classified as white or non-white (pardo or black).

\section{Blood sample collection for molecular analyses}

Approximately $10 \mathrm{~mL}$ of venous blood were drawn from each subject for molecular analyses. Until 2010, samples were collected and stored without processing at $-20^{\circ} \mathrm{C}$ until DNA isolation. Samples collected between 2015 and 2018 were centrifuged for $15 \mathrm{~min}$ at $1000 \boldsymbol{g}$ at $4^{\circ} \mathrm{C}$ within $3 \mathrm{~h}$ from collection for the separation of plasma and blood cells. Plasma samples were then aliquoted and stored at $-70^{\circ} \mathrm{C}$ until RNA isolation and the cellular component was kept at $-20^{\circ} \mathrm{C}$ until DNA isolation. In this study, we used the DNA samples of the 546 T2DM patients and 139 blood donors for the genotyping of the rs767649 polymorphism and RNA samples of 60 T2DM patients ( 20 without DR, 20 with NPDR and 20 with PDR) and 20 blood donors for the quantification of the plasma levels of miR-155.

\section{DNA isolation and genotyping}

DNA was isolated from peripheral white blood cells by a standard salting out method (28). Genotyping of the rs767649 polymorphism in the pre-MIR155 gene was done by real-time PCR using a pre-designed assay containing specific primers and hydrolysis probes (TaqMan ${ }^{\circledR}$ Genotyping Assay, assay ID: C_2212229_10; Thermo Fisher Scientific). Amplification reactions were done in a $7 \mu \mathrm{L}$ total reaction volume containing $20 \mathrm{ng}$ of genomic DNA, TaqMan Genotyping Master Mix (1x) (Thermo Fisher Scientific) and genotyping assay (1x). Reactions were loaded into a real-time PCR thermal cycler (StepOnePlus Real-Time PCR System; Thermo Fisher Scientific) and heated under the usual conditions specified by the manufacturer.

To ensure the accuracy of the genotyping data, a sample of each genotype was used in all PCR runs, the investigator who performed the genotyping was blinded to the patients' clinical condition and DR status and the genotypes were determined independently by two investigators. Seventy of the 685 samples $(10.2 \%)$ were randomly selected to be re-genotyped. Five samples did not amplify and the remaining had a concordance rate of $100 \%$.

\section{miRNA isolation and quantification}

miRNAs were isolated from $495 \mu \mathrm{L}$ of plasma using the mirVana PARIS kit with enrichment for small RNAs (Ambion; Thermo Fisher Scientific). After protein denaturation, plasma samples were spiked-in with $50 \mathrm{pM}$ of a synthetic miRNA from Caenorhabditis elegans (cel-miR-39; Qiagen) to control for variations during the isolation and quantification procedures.

Plasma levels of miR-155 were quantified by RT-quantitative PCR (RT-qPCR) in two separate reactions. First, RNA was reverse transcribed into cDNA and then cDNA was amplified by qPCR. RT reactions were done in a $15 \mu \mathrm{L}$ total reaction volume containing $10 \mathrm{ng}$ of the isolated RNA using a commercial kit according to the manufacturer's protocol (TaqMan ${ }^{\circledR}$ MicroRNA RT; Thermo Fisher Scientific). Reactions were incubated in a standard thermal cycler (PTC-150; MJ Research, Waltham, USA) for $30 \mathrm{~min}$ at $16^{\circ} \mathrm{C}, 30 \mathrm{~min}$ at $42^{\circ} \mathrm{C}$ and $5 \mathrm{~min}$ at $85^{\circ} \mathrm{C}$. Then, $2 \mu \mathrm{L}$ of the cDNA reaction mixture were amplified in duplicate reactions using pre-designed miRNA assays, containing specific primers and probes (Thermo Fisher Scientific) for cel-miR-39-3p (ID number 000200) and hsa-miR-155-5p (ID number 002623). In addition to the cDNA, the $15 \mu \mathrm{L}$ PCR reactions contained $0.75 \mu \mathrm{L}$ of the assay, $7.5 \mu \mathrm{L}$ of universal PCR master mix (no UNG) and $4.75 \mu \mathrm{L}$ of nuclease-free water. Amplification reactions were incubated for $10 \mathrm{~min}$ at $95^{\circ} \mathrm{C}$, followed by 45 cycles of $15 \mathrm{~s}$ at $95^{\circ} \mathrm{C}$ and $1 \mathrm{~min}$ at $60^{\circ} \mathrm{C}$ on StepOnePlus RealTime PCR System (Thermo Fisher Scientific). Raw Cq values $>40$ were considered as undetectable.

The comparative method $\left(2^{-\Delta \Delta C q}\right)$ (29) was used to determine the plasma levels of miR-155 in T2DM patients and blood donors, considering the spiked-in cel-miR-39 as the reference gene and a pool of cDNA samples as the reference sample (calibrator). The pool samples were obtained from nine subjects with T2DM randomly selected from each group (four without DR, three with NPDR and two with PDR). For statistical analysis, fold-change values were log2-transformed.

\section{Statistical analysis}

Categorical data are shown as absolute frequency (percentage), percentage or relative frequency, and continuous variables are expressed as mean \pm s.D. or median (25th and 75th percentiles). Data normality was

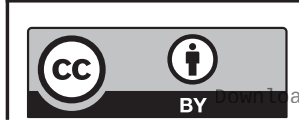

This work is licensed under a Creative Commons Attribution 4.0 International License. 
assessed using the Shapiro-Wilk test. Categorical data were compared between groups of subjects by $\chi^{2}$-square test, followed by Bonferroni correction for multiple pairwise comparisons where appropriate or Fisher's exact test. The $\chi^{2}$ test was also used to test for deviations from the Hardy-Weinberg equilibrium. Continuous data were compared by independent Student $t$-test, MannWhitney $U$, one-way ANOVA or Kruskal-Wallis, followed by the Tukey or Dunn post hoc analysis, as appropriate. Correlation between miR-155 and clinical variables was evaluated using the Pearson (r) or the Spearman $\left(\mathrm{r}_{\mathrm{s}}\right)$ correlation coefficient, as indicated by the normality test. Association of the rs767649 polymorphism with DR was evaluated by logistic regression analysis. Considering the very low frequency of the AA genotype, we tested only the dominant model for the A allele (AA+TA vs TT). Statistical analyses were done using SPSS, version 18.0 (SPSS Inc.) and WinPEPI version 11.50 (30) statistical packages. Two-tailed $P$ values $<0.05$ were considered as statistically significant. The genotyping and expression data generated during this study are available in Supplementary Table 1 (see section on supplementary data given at the end of this article) and in a public repository (https://doi. org/10.6084/m9.figshare.9789260).

As DR was the primary outcome of our study and no previous study has investigated the association of the rs767649 polymorphism with this complication, sample size and study power were not determined a priori. In relation to the plasma levels of miR-155, we used the results obtained in a Chinese study (19) for the sample size calculation. The number of samples required to detect a minimum difference of 0.5 in the levels of miR- 155 with a statistical power of $90 \%$ at a significance level of 0.05 was 12 ( 6 cases and 6 controls). Sample size was estimated using the WinPEPI statistical software.

\section{Results}

\section{Characteristics of study subjects}

T2DM patients were predominantly older, white and female (Table 1). As expected, most blood donors were white $(69 \%)$, male $(60 \%)$ and younger than T2DM subjects (mean age of $44 \pm 8$ years, ranging from 30 to 69 years; $P<0.010$ for the comparison of these three variables between patients and blood donors). Subjects with PDR were older and more often male, had diabetes for longer, were more often insulin users, had lower BMI and lower eGFR as compared with those without DR. Except for the diabetes duration and use of insulin, patients with NPDR had a similar profile to those without DR (Table 1).

\section{rs767649 polymorphism in blood donors and T2DM patients with and without DR}

Genotype frequencies were in agreement with those predicted by the Hardy-Weinberg equation in blood donors and T2DM patients. As shown in Table 2, genotype and allele frequencies were similar in blood donors and T2DM. In relation to DR, however, the frequency of the carriers of the A allele as well as the A allele tended to

Table 1 Clinical and demographic characteristics of T2DM patients with and without DR.

\begin{tabular}{l}
\hline Characteristic \\
\hline Age (years) \\
Male gender, $n(\%)$ \\
Non-white, $n(\%)$ \\
Diabetes duration (years) \\
Insulin use (\%) \\
HbA1c (\%) \\
Body mass index $\left(\mathrm{kg} / \mathrm{m}^{2}\right)$ \\
History of smoking $(\%)$ \\
Hypertension $(\%)$ \\
Systolic BP $(\mathrm{mmHg})$ \\
Diastolic BP $(\mathrm{mmHg})$ \\
eGFR (mL/min/1.73 m²) \\
Total cholesterol $(\mathrm{mmol} / \mathrm{L})$ \\
HDL cholesterol $(\mathrm{mmol} / \mathrm{L})$ \\
LDL cholesterol $(\mathrm{mmol} / \mathrm{L})$
\end{tabular}

\begin{tabular}{c}
\hline All patients $(n=546)$ \\
\hline $60.9 \pm 9.0$ \\
$251(46.0)$ \\
$77(14.1)$ \\
$14.7 \pm 7.9$ \\
54.4 \\
$7.6 \pm 1.9$ \\
$30.1 \pm 5.6$ \\
44.9 \\
77.5 \\
$141 \pm 23$ \\
$83 \pm 13$ \\
$92(73-103)$ \\
$5.1 \pm 1.4$ \\
$1.14 \pm 0.32$ \\
$3.0 \pm 1.1$
\end{tabular}

\begin{tabular}{c}
\hline Without DR $(n=244)$ \\
\hline $60.1 \pm 9.3^{a}$ \\
$93(38.1)^{a}$ \\
$36(14.8)$ \\
$13.1 \pm 7.0^{a}$ \\
$38.9^{a}$ \\
$7.6 \pm 2.0^{a, b}$ \\
$31.0 \pm 6.3^{a}$ \\
50.0 \\
78.3 \\
$140 \pm 22$ \\
$84 \pm 14$ \\
$95(81-104)^{a}$ \\
$5.0 \pm 1.2$ \\
$1.16 \pm 0.30$ \\
$2.9 \pm 1.0$
\end{tabular}

\begin{tabular}{c}
\hline NPDR $(n=161)$ \\
\hline $60.8 \pm 9.0^{\mathrm{a}, \mathrm{b}}$ \\
$74(46.0)^{\mathrm{a}, \mathrm{b}}$ \\
$20(12.4)$ \\
$15.0 \pm 8.1^{\mathrm{b}}$ \\
$64.6^{\mathrm{b}}$ \\
$8.0 \pm 2.0^{\mathrm{a}}$ \\
$29.8 \pm 4.9^{\mathrm{a}, \mathrm{b}}$ \\
41.0 \\
79.5 \\
$143 \pm 23$ \\
$82 \pm 11$ \\
$94(79-103)^{\mathrm{a}}$ \\
$5.2 \pm 1.6$ \\
$1.12 \pm 0.35$ \\
$3.0 \pm 1.1$
\end{tabular}

\begin{tabular}{c}
\hline PDR $(n=141)$ \\
\hline $62.4 \pm 8.3^{\mathrm{b}}$ \\
$84(59.6)^{\mathrm{b}}$ \\
$21(14.9)$ \\
$17.1 \pm 8.6^{\mathrm{b}}$ \\
$70.2^{\mathrm{b}}$ \\
$7.3 \pm 1.7^{\mathrm{b}}$ \\
$28.6 \pm 4.5^{\mathrm{b}}$ \\
41.1 \\
73.8 \\
$142 \pm 24$ \\
$83 \pm 12$ \\
$76(42-98)^{\mathrm{b}}$ \\
$5.3 \pm 1.3$ \\
$1.11 \pm 0.33$ \\
$3.2 \pm 1.2$
\end{tabular}

\begin{tabular}{r} 
P value \\
\hline 0.050 \\
$<0.001$ \\
0.766 \\
$<0.001$ \\
$<0.001$ \\
0.018 \\
$<0.001$ \\
0.173 \\
0.453 \\
0.741 \\
0.702 \\
$<0.001$ \\
0.123 \\
0.098 \\
0.189
\end{tabular}

Data are expressed as mean \pm s.D., median (25th-75th percentiles), number (percentage) or percentage. Pairwise comparisons with statistically significant differences after correction for multiple testing are indicated with the following terminology: means, medians or percentages indicated with the same letter do not differ significantly at alpha $<0.05$, and means, medians or percentages indicated with different letters are significantly different.

https://ec.bioscientifica.com https://doi.org/10.1530/EC-19-0446 (c) 2019 The authors Published by Bioscientifica Ltd

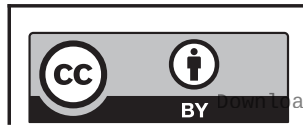

This work is licensed under a Creative Commons Attribution 4.0 International License. ded from Bioscientifica.com at 04/26/2023 12:53:26PM 
Table 2 Genotype and allele frequencies of the rs767649 polymorphism in the pre-MIR155 gene in blood donors and T2DM patients with and without DR.

\begin{tabular}{l}
\hline Polymorphism \\
\hline Genotype \\
TT \\
TA \\
AA \\
Allele \\
T \\
A \\
\hline
\end{tabular}

\begin{tabular}{c}
$\begin{array}{c}\text { Blood donors } \\
(n=139)\end{array}$ \\
\hline $124(89.2)$ \\
$14(10.1)$ \\
$1(0.7)$ \\
\\
0.94 \\
0.06 \\
\hline
\end{tabular}

\begin{tabular}{c}
\hline $\begin{array}{c}\text { All patients } \\
(n=546)\end{array}$ \\
\hline $469(85.9)$ \\
$75(13.7)$ \\
$2(0.4)$ \\
0.93 \\
0.07 \\
\hline
\end{tabular}

\begin{tabular}{c}
\hline P value \\
\hline 0.441 \\
0.463
\end{tabular}

\begin{tabular}{c}
$\begin{array}{c}\text { Without DR } \\
(n=244)\end{array}$ \\
\hline $221(90.6)$ \\
$21(8.6)^{\mathrm{a}}$ \\
$2(0.8)$
\end{tabular}
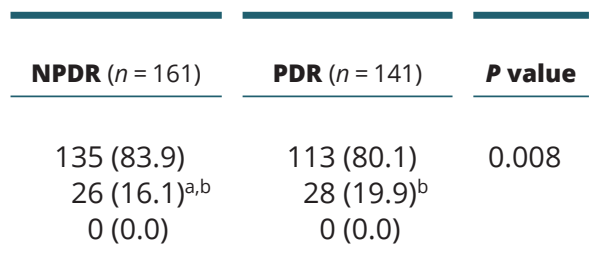

Data are expressed as number (percentage) or relative frequency. Pairwise comparisons with statistically significant differences after correction for multiple testing are indicated with the following terminology: percentages indicated with the same letter do not differ significantly at alpha <0.05, and percentages indicated with different letters are significantly different.

increase according to the presence and severity of this complication (Table 2). In fact, the carriership of the A allele was more frequent in patients with DR (NPDR + PDR) than in those without it ( 17.9 vs $9.4 \%$, respectively; $P=0.007$ ). Similarly, the A allele was more frequent in patients with DR as compared to those without this complication (8.9 vs $5.1 \%$, respectively; $P=0.021$ ).

Under the dominant model, the A allele was associated with an increased risk of DR (odds ratio $(\mathrm{OR})=2.09 ; 95 \%$ confidence interval $(\mathrm{CI})=1.24-3.52 ; \quad P=0.005)$. After controlling for the other variables that were also associated with this complication in the univariate analyses, namely, male gender (yes/no), diabetes duration (years), smoking history (positive/negative), BMI $\left(\mathrm{kg} / \mathrm{m}^{2}\right)$, insulin use (yes/no), eGFR $\left(\mathrm{mL} / \mathrm{min} / 1.73 \mathrm{~m}^{2}\right)$ and total cholesterol $(\mathrm{mmol} / \mathrm{L})$, the A allele remained significantly associated with DR in the final model (Table 3).

\section{Plasma levels of miR-155 in blood donors and T2DM patients with and without DR}

To evaluate the plasma levels of miR-155, 20 samples were randomly selected from each group of T2DM patients. Patients had a mean age of $63 \pm 8$ years (ranging from 43 to 84 years), a mean diabetes duration of $18 \pm 8$ years (ranging from 5 to 39 years) and a mean HbA1c of $8.4 \pm 1.5 \%$ (ranging from 5.5 to $11.3 \%$ ). They were predominantly female $(60 \%)$ and white (70\%). Although blood donors were not individually matched to T2DM patients, we selected a subgroup of 20 blood donors having the same proportion of females (55\%) and whites (70\%) as the patient group to quantify the levels of miR-155. Indeed, the plasma levels of miR-155 were lower in T2DM patients than in blood donors, but they did not differ according to the presence or severity of DR among T2DM patients (Fig. 1 and Table 4).

\section{Correlation of plasma levels of miR-155 with the rs767649 polymorphism and clinical characteristics}

Considering that all but one of the 20 blood donors who had the plasma levels of miR-155 quantified were homozygous for the $\mathrm{T}$ allele of the rs767649 polymorphism, we could only verify whether there was an association between this gene variant and the expression of miR-155 in T2DM patients. The plasma levels of miR-155 were not different in subjects with the TT genotype $(n=42)$ as compared to those carrying the A allele $(n=18)(1.06(0.15-2.23)$ vs $0.82(0.41-2.46)$, respectively; $P=0.995)$. In addition, few correlations were found between the plasma levels of miR-155 and clinical and demographic characteristics in T2DM patients. Specifically, the median levels of miR-155 were two-fold higher in non-whites $(n=18)$ than in whites $(n=42)(1.66(0.81-2.61)$ vs $0.82(0.11-2.08)$, respectively; $P=0.019)$, and the miR-155 was weakly correlated with diastolic blood pressure (BP) $\left(\mathrm{r}_{\mathrm{s}}=-0.27 ; P=0.036\right)$.

\section{Discussion}

In this study, we detected an independent association of the A allele of the rs767649 polymorphism in the

Table 3 Multiple logistic regression (final model) for the association of the rs767649 polymorphism in the pre-MIR155 gene with DR.

\begin{tabular}{l} 
Variable \\
\hline AA + TA genotypes \\
(vs TT genotype) \\
Body mass index $\left(\mathrm{kg} / \mathrm{m}^{2}\right)$ \\
Insulin use $(\mathrm{yes} / \mathrm{no})$ \\
eGFR $\left(\mathrm{mL} / \mathrm{min} / 1.73 \mathrm{~m}^{2}\right)$ \\
Total cholesterol $(\mathrm{mmol} / \mathrm{L})$
\end{tabular}

\begin{tabular}{crrr}
\hline Adjusted OR $(95 \% \mathrm{Cl})$ & & P value \\
\cline { 1 - 1 } $2.12(1.12-4.01)$ & & 0.020 \\
& & \\
$0.94(0.90-0.98)$ & & 0.004 \\
$3.78(2.42-5.91)$ & & $<0.001$ \\
$0.99(0.98-1.00)$ & & 0.007 \\
$1.22(1.03-1.44)$ & & 0.024 \\
\hline
\end{tabular}

This work is licensed under a Creative Commons Attribution 4.0 International License. ded from Bioscientifica.com at 04/26/2023 12:53:26PM 


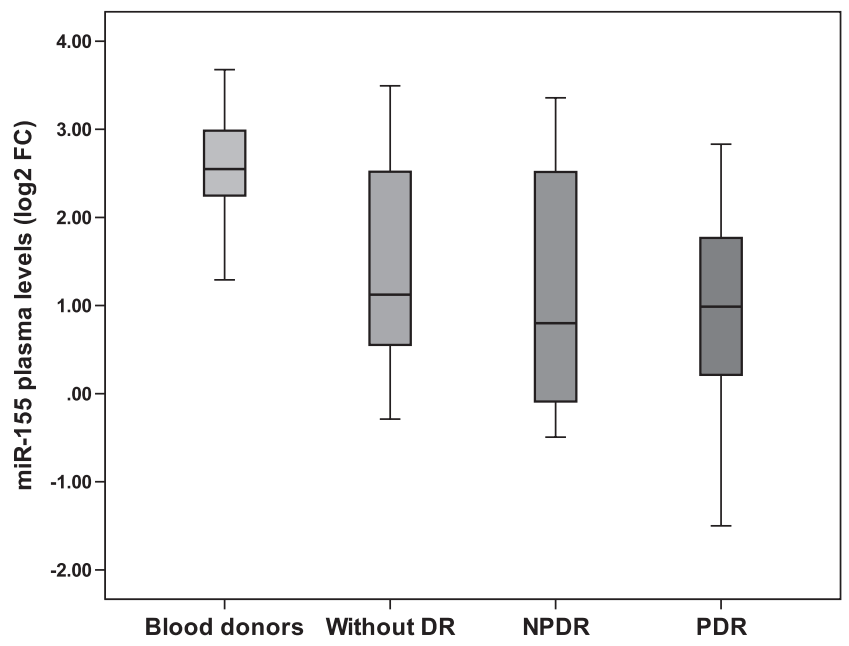

Figure 1

Comparative analysis of plasma levels of miR-155 in blood donors and T2DM patients with and without DR. Expression levels are expressed as $\log 2$ fold-change. Corrected $P$ values $<0.010$ for the pairwise comparisons between blood donors and all groups of T2DM patients (without DR, NPDR and PDR).

pre-MIR155 gene with DR in T2DM outpatients from two tertiary hospitals in Southern Brazil. We also reported that blood donors had higher plasma levels of miR-155 than T2DM patients, and among diabetic patients, the miR-155 levels were higher in non-whites than in whites. However, miR-155 expression did not vary according to the presence or severity of DR or according to rs767649 genotypes.

The frequency of the minor A allele of the rs767649 polymorphism was quite similar to that previously reported in our population (22), and the genotype and allele frequencies were almost the same in blood donors and T2DM patients. These findings contrast with those reported in studies from Brazil (22) and Italy (23), in which the A allele was associated with a lower risk of T1DM and T2DM, respectively. However, this discrepancy is not unexpected, because our study was not

Table 4 Plasma levels of miR-155 in blood donors and T2DM patients with and without DR.

\begin{tabular}{|c|c|}
\hline Subject groups & miR-155 (Log2 FC) \\
\hline Blood donors $(n=20)$ & 2.55 (2.24-3.00) \\
\hline All patients $(n=60)$ & $0.99(0.19-2.29)$ \\
\hline$P$ value $^{a}$ & $<0.001$ \\
\hline Without DR $(n=20)$ & $1.12(0.51-2.62)$ \\
\hline $\operatorname{NPDR}(n=20)$ & $0.80(-0.15$ to 2.59$)$ \\
\hline $\operatorname{PDR}(n=20)$ & 0.99 (0.19-1.92) \\
\hline$P$ value ${ }^{b}$ & 0.509 \\
\hline
\end{tabular}

Data are expressed as median (25th-75th percentiles).

${ }^{a}$ Comparing blood donors with all patients. ${ }^{b}$ Comparing patients without DR, NPDR and PDR.

FC, fold-change. designed to investigate the association of the rs767649 polymorphism with $\mathrm{T} 2 \mathrm{DM}$ and $20 \%$ of the blood donors in our population have HbA1c levels compatible with prediabetes or diabetes. This could have led to the similar distribution frequency of this polymorphism in blood donors and T2DM patients. In relation to DR, to the best of our knowledge, no study has investigated the association between the rs767649 polymorphism and this diabetic complication. We found that the A allele was associated with a two-fold increased risk of DR in T2DM patients even after controlling for clinical covariates.

Our results regarding the expression of miR-155 are in accordance with those reported in populations from Mexico (31), Egypt (32), Iran (33), Germany (34) and China (13), in which the circulating levels of miR-155 were downregulated in subjects with T2DM in comparison to healthy controls. In a streptozotocin (STZ)-nicotinamide-induced rat model of T2DM, the miR-155 expression was lower in PBMC, kidney, heart, aorta and sciatic nerve obtained from diabetic rats than in their non-diabetic counterparts (35). In genetically modified mice, the overexpression of miR-155 resulted in hypoglycaemia, improved glucose tolerance and enhanced insulin sensitivity in peripheral tissues, which were caused, at least in part, by enhanced glucose uptake and enhanced glycolysis, whereas the deficiency of miR-155 led to opposite effects (13).

In relation to DR, our results are in agreement with an Italian study in T1DM, in which miR-155-5p isolated from plasma extracellular vesicles was markedly downregulated in patients with PDR in comparison to healthy subjects (18). However, these results are opposite to those reported in a Chinese study that found higher PBMC levels of miR-155 in T2DM patients with PDR and NPDR in comparison to those without DR and healthy controls (19). These contrasting findings might be due, at least in part, to the ethnicity, patient's profile and methodological differences in the quantification of miR-155, including the RNA isolation, qPCR and estimation of gene expression (12). Experimental studies on murine models showed that miR-155 regulates gene expression of its several targets in a biological context- and cell-type-dependent manner (36), exerting both pro- and anti-inflammatory effects (37), and may have dual effects on adaptive neovascularization (38). Given the lack of experimental evidence on the effects of miR-155 on retinal function in diabetes, it is hard to define what would be expected in relation to its expression in DR.

Previous studies have investigated the effect of miR-155 on retinal apoptosis and angiogenesis predominantly in

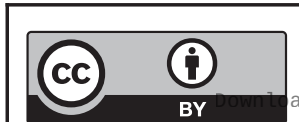

This work is licensed under a Creative Commons Attribution 4.0 International License. ded from Bioscientifica.com at $04 / 26 / 2023$ 12:53:26PM 
cell culture and murine models that resemble retinopathy of prematurity (ROP) or age-related macular degeneration (AMD) $(15,17,39,40,41)$. In this scenario, overexpression of miR-155 in the retina seemed to be detrimental (15, $17,39)$. In contrast, the levels of endogenous miR-155 were decreased in retinal pigment epithelium/choroidal tissues after laser photocoagulation in mice. In this model, the intravitreous injection of miR-155 mimics markedly reduced the expression of vascular endothelial growth factor, subretinal leakage and choroidal neovascularization (40). Interestingly, an Italian study showed that the retinal and circulating levels of miRNAs could vary in the same model. miR-155 was upregulated in the retina of amyloid beta injected rats, whereas it was downregulated in serum of both AMD patients and rats (41).

Recently, a bionformatic analysis of visual perceptionrelated genes using transcriptomic data obtained from retina samples from two mouse models of diabetes after 3 months of hyperglycaemia suggested that the expression of miR-155-5p should be downregulated in DR (42). This proposition was based on the competing endogenous RNAs (ceRNAs) hypothesis, according to which multiple miRNA targets compete with each other to bind the miRNA (43). Thus, we speculate that the downregulation of miR-155 may be detrimental in retina and this might result in even less miR-155 circulating in plasma, which could explain, at least in part, the decreased levels of miR-155 in diabetic patients in our study.

Apart from this, we have not found any difference in the plasma levels of miR-155 between T2DM patients carrying the A allele and those homozygous for the $\mathrm{T}$ allele. The few studies that evaluated the functionality of the rs767649 polymorphism found opposite effects on the miR-155 transcriptional activity, depending on the cell line utilized $(44,45,46)$. Due to the lack of functional assays of the rs767649 polymorphism in retinal cells, its potential effect on DR is still unknown. Thus, in the absence of consistent experimental evidence regarding the functionality of this polymorphism, it is hard to explain how the A allele was associated with DR in our population, whereas the plasma levels of miR-155 were not related to it. One plausible explanation is that the rs767649 polymorphism might be in linkage disequilibrium with an adjacent region within or nearby the pre-MIR155 that harbours the true causal variant. Another possible reason is that the plasma levels measured at one time point may not reflect their levels at the onset of DR.

Finally, our findings should be considered in light of some study limitations. First, its case-control design does not allow to establish a cause-and-effect relationship of the plasma levels of miR-155 with DR and T2DM. Second, eye fundus was examined using ophthalmoscopy in approximately half of the patients. As this method has reduced sensitivity to grade lower levels of DR (47), some subjects with mild NPDR might have been included in the group without DR. However, this would lead toward negative results. In spite of the limitations, our findings are novel as this is the first study, to our knowledge, to evaluate and report that a putatively functional polymorphism in the pre-MIR155 gene is associated with DR. They also corroborate previous reports that circulating levels of miR-155 are downregulated in T2DM, supporting the need of additional studies to better understand the relationship of miR-155 with DR and T2DM and to evaluate whether it could have clinical value in T2DM patients.

In conclusion, the $\mathrm{A}$ allele of the rs767649 polymorphism in the pre-MIR155 gene was independently associated with DR in T2DM outpatients from a South Brazilian population. The plasma levels of miR-155 were higher in blood donors than in T2DM patients, but they were not associated with DR. Moreover, the rs767649 polymorphism was not associated with the plasma levels of miR-155. Taken together, our findings provide suggestive evidence that miR-155 may be involved in the pathogenesis of DR and/or T2DM and should be investigated further to evaluate its usefulness as biomarker of these conditions.

\section{Supplementary data}

This is available on the journal website at https://doi.org/10.1530/EC-19-0446. The supplementary data is also available on figshare:

Supplementary Table 1: https://doi.org/10.6084/m9.figshare.9789260

\section{Declaration of interest}

The authors declare that there is no conflict of interest that could be perceived as prejudicing the impartiality of the research reported.

\section{Funding}

This work was supported by Fundação de Amparo à Pesquisa do Estado do Rio Grande do Sul (FAPERGS), Porto Alegre, Brazil (grant PqG 19942551/13-4 to K G S), Fundo de Incentivo à Pesquisa e Eventos do Hospital de Clínicas de Porto Alegre (FIPE-HCPA), Porto Alegre, Brazil (grant number 14-0645 to D C) and the Coordenação de Aperfeiçoamento de Pessoal de Nível Superior - Brasil (CAPES) - Finance Code 001 (E R P was a recipient of a postdoctoral scholarship and R C S is currently a recipient of a scholarship from this agency).

\section{References}

1 Lynch SK \& Abràmoff MD. Diabetic retinopathy is a neurodegenerative disorder. Vision Research 2017139 101-107. (https://doi.org/10.1016/j.visres.2017.03.003)

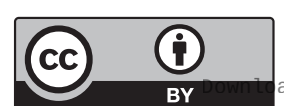


2 Pearce I, Simó R, Lövestam-Adrian M, Wong DT \& Evans M. Association between diabetic eye disease and other complications of diabetes: implications for care. Diabetes, Obesity and Metabolism 201921 467-478. (https://doi.org/10.1111/dom.13550)

3 Rübsam A, Parikh S \& Fort PE. Role of inflammation in diabetic retinopathy. International Journal of Molecular Sciences 201819 E942. (https://doi.org/10.3390/ijms19040942)

4 O'Brien J, Hayder H, Zayed Y \& Peng C. Overview of microRNA biogenesis, mechanisms of actions, and circulation. Frontiers in Endocrinology 20189 402. (https://doi.org/10.3389/ fendo.2018.00402)

5 Shafabakhsh R, Aghadavod E, Mobini M, Heidari-Soureshjani R \& Asemi Z. Association between microRNAs expression and signaling pathways of inflammatory markers in diabetic retinopathy. Journal of Cellular Physiology 2019234 7781-7787. (https://doi.org/10.1002/ jcp.27685)

6 Joglekar MV, Januszewski AS, Jenkins AJ \& Hardikar AA. Circulating microRNA biomarkers of diabetic retinopathy. Diabetes 201665 22-24. (https://doi.org/10.2337/dbi15-0028)

7 Cammaerts S, Strazisar M, De Rijk P \& Del Favero J. Genetic variants in microRNA genes: impact on microRNA expression, function, and disease. Frontiers in Genetics 20156 186. (https://doi.org/10.3389/ fgene.2015.00186)

8 Zhang Y, Bai R, Liu C, Ma C, Chen X, Yang J \& Sun D. MicroRNA single-nucleotide polymorphisms and diabetes mellitus: a comprehensive review. Clinical Genetics 201995 451-461. (https:// doi.org/10.1111/cge.13491)

9 McAuley AK, Dirani M, Wang JJ, Connell PP, Lamoureux EL \& Hewitt AW. A genetic variant regulating miR-126 is associated with sight threatening diabetic retinopathy. Diabetes and Vascular Disease Research 201512 133-138. (https://doi. org/10.1177/1479164114560160)

10 Kaidonis G, Gillies MC, Abhary S, Liu E, Essex RW, Chang JH, Pal B, Sivaprasad S, Pefkianaki M, Daniell M, et al. A single-nucleotide polymorphism in the microRNA-146a gene is associated with diabetic nephropathy and sight-threatening diabetic retinopathy in Caucasian patients. Acta Diabetologica 201653 643-650. (https://doi. org/10.1007/s00592-016-0850-4)

11 Testa U, Pelosi E, Castelli G \& Labbaye C. -146 and miR-155: two key modulators of immune response and tumor development. Noncoding RNA 20173 E22. (https://doi.org/10.3390/ncrna3030022)

12 Berber P, Grassmann F, Kiel C \& Weber BH. An eye on age-related macular degeneration: the role of microRNAs in disease pathology. Molecular Diagnosis and Therapy 201721 31-43. (https://doi. org/10.1007/s40291-016-0234-z)

13 Lin X, Qin Y, Jia J, Lin T, Lin X, Chen L, Zeng H, Han Y, Wu L, Huang $\mathrm{S}$, et al. MiR-155 enhances insulin sensitivity by coordinated regulation of multiple genes in mice. PLoS Genetics 201612 e1006308. (https://doi.org/10.1371/journal.pgen.1006308)

14 Kovacs B, Lumayag S, Cowan C \& Xu S. MicroRNAs in early diabetic retinopathy in streptozotocin-induced diabetic rats. Investigative Ophthalmology and Visual Science 201152 4402-4409. (https://doi. $\operatorname{org} / 10.1167 /$ iovs.10-6879)

15 Zhuang Z, Xiao-qin HH, Tian SY, Lu ZJ, Zhang TZ \& Bai YL. Downregulation of microRNA-155 attenuates retinal neovascularization via the PI3K/Akt pathway. Molecular Vision 201513 1173-1184.

16 Decembrini S, Bressan D, Vignali R, Pitto L, Mariotti S, Rainaldi G, Wang X, Evangelista M, Barsacchi G \& Cremisi F. MicroRNAs couple cell fate and developmental timing in retina. PNAS $2009 \mathbf{1 0 6}$ 21179-21184. (https://doi.org/10.1073/pnas.0909167106)

17 Yan L, Lee S, Lazzaro DR, Aranda J, Grant MB \& Chaqour B. Single and compound knock-outs of microRNA (miRNA)-155 and its angiogenic gene target CCN1 in mice alter vascular and neovascular growth in the retina via resident microglia. Journal of Biological Chemistry 2015290 23264-23281. (https://doi.org/10.1074/jbc. M115.646950)
18 Mazzeo A, Beltramo E, Lopatina T, Gai C, Trento M \& Porta M. Molecular and functional characterization of circulating extracellular vesicles from diabetic patients with and without retinopathy and healthy subjects. Experimental Eye Research 2018176 69-77. (https:// doi.org/10.1016/j.exer.2018.07.003)

19 Yang TT, Song SJ, Xue HB, Shi DF, Liu CM \& Liu H. Regulatory T cells in the pathogenesis of type 2 diabetes mellitus retinopathy by miR155. European Review for Medical and Pharmacological Sciences 201519 2010-2015.

20 Elton TS, Selemon H, Elton SM \& Parinandi NL. Regulation of the MIR155 host gene in physiological and pathological processes. Gene 2013532 1-12. (https://doi.org/10.1016/j.gene.2012.12.009)

21 Li C, He H, Liu A, Liu H, Huang H, Zhao C, Jing L, Ni J, Yin L, Hu S, et al. Natural functional SNPs in miR-155 alter its expression level, blood cell counts, and immune responses. Frontiers in Immunology 20167 295. (https://doi.org/10.3389/fimmu.2016.00295)

22 Assmann TS, Duarte GCK, Brondani LA, Freitas PHO, Martins ÉM, Canani LH \& Crispim D. Polymorphisms in genes encoding miR-155 and miR-146a are associated with protection to type 1 diabetes mellitus. Acta Diabetologica 201754 433-441. (https://doi. org/10.1007/s00592-016-0961-y)

23 Latini A, Spallone V, D'Amato C, Novelli G, Borgiani P \& Ciccacci C. A common polymorphism in miR155 gene promoter region is associated with a lower risk to develop type 2 diabetes. Acta Diabetologica 201956 717-718. (https://doi.org/10.1007/s00592-018-1277-x)

24 American Diabetes Association. Classification and diagnosis of diabetes. Diabetes Care 201538 S8-S16. (https://doi.org/10.2337/ dc15-S005)

25 Buffon MP, Carpena MP, Sortica DA, Santer A, Carlessi R, Souza BM, Edelweiss MI, Berger M, Crispim D \& Canani LH. rs1888747 polymorphism in the FRMD3 gene, gene and protein expression: role in diabetic kidney disease. Diabetology and Metabolic Syndrome 20168 3. (https://doi.org/10.1186/s13098-015-0121-5)

26 Levey AS, Stevens LA, Schmid CH, Zhang YL, Castro 3rd AF, Feldman HI, Kusek JW, Eggers P, Van Lente F, Greene T, et al. A new equation to estimate glomerular filtration rate. Annals of Internal Medicine 2009150 604-612. (https://doi.org/10.7326/0003-4819150-9-200905050-00006)

27 American Academy of Ophthalmology Retina/Vitreous Panel. Preferered peractice pattern ${ }^{\circledR}$ guidelines. Diabetic retinopathy. San Francisco, CA: American Academy of Ophthalmology, 2017. (available at: www.aao.org/ppp)

28 Lahiri DK \& Nurnberger Jr JI. A rapid non-enzymatic method for the preparation of HMW DNA from blood for RFLP studies. Nucleic Acids Research 199119 5444. (https://doi.org/10.1093/nar/19.19.5444)

29 Schmittgen TD \& Livak KJ. Analyzing real-time PCR data by the comparative C(T) method. Nature Protocols 20083 1101-1108. (https://doi.org/10.1038/nprot.2008.73)

30 Abramson JH. WINPEPI updated: computer programs for epidemiologists, and their teaching potential. Epidemiologic Perspectives and Innovations 20118 1. (https://doi.org/10.1186/1742-5573-8-1)

31 Corral-Fernández NE, Salgado-Bustamante M, Martínez-Leija ME, Cortez-Espinosa N, García-Hernández MH, Reynaga-Hernández E, Quezada-Calvillo R \& Portales-Pérez DP. Dysregulated miR-155 expression in peripheral blood mononuclear cells from patients with type 2 diabetes. Experimental and Clinical Endocrinology and Diabetes 2013121 347-353. (https://doi.org/10.1055/s-0033-1341516)

32 El Samaloty NM, Hassan ZA, Hefny ZM \& Abdelaziz DHA. Circulating microRNA-155 is associated with insulin resistance in chronic hepatitis C patients. Arab Journal of Gastroenterology 201920 1-7. (https://doi.org/10.1016/j.ajg.2019.01.011)

33 Mazloom H, Alizadeh S, Pasalar P, Esfahani EN \& Meshkani R. Downregulated microRNA-155 expression in peripheral blood mononuclear cells of type 2 diabetic patients is not correlated with increased inflammatory cytokine production. Cytokine 201576 403-408. (https://doi.org/10.1016/j.cyto.2015.07.007)

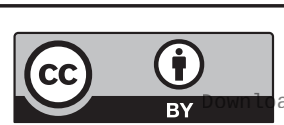

This work is licensed under a Creative Commons Attribution 4.0 International License. ded from Bioscientifica, com at 04/26/2023 12:53:26PM 
34 Elgheznawy A, Shi L, Hu J, Wittig I, Laban H, Pircher J, Mann A, Provost P, Randriamboavonjy V \& Fleming I. Dicer cleavage by calpain determines platelet microRNA levels and function in diabetes. Circulation Research 2015117 157-165. (https://doi. org/10.1161/CIRCRESAHA.117.305784)

35 Khamaneh AM, Alipour MR, Sheikhzadeh Hesari F \& Ghadiri Soufi F. A signature of microRNA-155 in the pathogenesis of diabetic complications. Journal of Physiology and Biochemistry $20157 \mathbf{1}$ 301-309. (https://doi.org/10.1007/s13105-015-0413-0)

36 Hsin JP, Lu Y, Loeb GB, Leslie CS \& Rudensky AY. The effect of cellular context on miR-155-mediated gene regulation in four major immune cell types. Nature Immunology 201819 1137-1145. (https:// doi.org/10.1038/s41590-018-0208-x)

37 Nejad C, Stunden HJ \& Gantier MP. A guide to miRNAs in inflammation and innate immune responses. FEBS Journal $2018 \mathbf{2 8 5}$ 3695-3716. (https://doi.org/10.1111/febs.14482)

38 Pankratz F, Bemtgen X, Zeiser R, Leonhardt F, Kreuzaler S, Hilgendorf I, Smolka C, Helbing T, Hoefer I, Esser JS, et al. MicroRNA-155 exerts cell-specific antiangiogenic but proarteriogenic effects during adaptive neovascularization. Circulation 2015131 1575-1589. (https://doi.org/10.1161/CIRCULATIONAHA.114.014579)

39 Bian M, Du X, Wang P, Cui J, Xu J, Gu J, Zhang T \& Chen Y. Combination of ginsenoside $\mathrm{Rb} 1$ and $\mathrm{Rd}$ protects the retina against bright light-induced degeneration. Scientific Reports $2017 \mathbf{7} 6015$. (https://doi.org/10.1038/s41598-017-06471-x)

40 Zhang P, Wang H, Luo X, Liu H, Lu B, Li T, Yang S, Gu Q, Li B, Wang F, et al. MicroRNA-155 inhibits polarization of macrophages to M2-type and suppresses choroidal neovascularization. Inflammation 201841 143-153. (https://doi.org/10.1007/s10753-017-0672-8)

41 Romano GL, Platania CBM, Drago F, Salomone S, Ragusa M, Barbagallo C, Di Pietro C, Purrello M, Reibaldi M, Avitabile T, et al.
Retinal and circulating miRNAs in age-related macular degeneration: an in vivo animal and human study. Frontiers in Pharmacology 20178 168. (https://doi.org/10.3389/fphar.2017.00168)

42 You ZP, Zhang YL, Li BY, Zhu XG \& Shi K. Bioinformatics analysis of weighted genes in diabetic retinopathy. Investigative Ophthalmology and Visual Science 201859 5558-5563. (https://doi.org/10.1167/ iovs.18-25515)

43 Salmena L, Poliseno L, Tay Y, Kats L \& Pandolfi PP. A ceRNA hypothesis: the Rosetta Stone of a hidden RNA language? Cell 2011 146 353-358. (https://doi.org/10.1016/j.cell.2011.07.014)

44 Xie K, Ma H, Liang C, Wang C, Qin N, Shen W, Gu Y, Yan C, Zhang K, Dai N, et al. A functional variant in miR-155 regulation region contributes to lung cancer risk and survival. Oncotarget 20156 42781-42792. (https://doi.org/10.18632/oncotarget.5840)

45 Wang S, Cao X, Ding B, Chen J, Cui M, Xu Y, Lu X, Zhang Z, He A \& Jin H. The rs767649 polymorphism in the promoter of miR-155 contributes to the decreased risk for cervical cancer in a Chinese population. Gene 2016595 109-114. (https://doi.org/10.1016/j. gene.2016.10.002)

46 Yang X, Peng J, Pang J, Wan W \& Chen L. A functional polymorphism in the promoter region of miR-155 predicts the risk of intracranial hemorrhage caused by rupture intracranial aneurysm. Journal of Cellular Biochemistry 2019120 18618-18628. (https://doi. org/10.1002/jcb.28785)

47 Lin DY, Blumenkranz MS, Brothers RJ \& Grosvenor DM. The sensitivity and specificity of single-field nonmydriatic monochromatic digital fundus photography with remote image interpretation for diabetic retinopathy screening: a comparison with ophthalmoscopy and standardized mydriatic color photography. American Journal of Ophthalmology 2002134 204-213. (https://doi. org/10.1016/s0002-9394(02)01522-2)

Received in final form 28 October 2019

Accepted 11 November 2019

Accepted Preprint published online 11 November 2019 (c) 2019 The authors Published by Bioscientifica Ltd

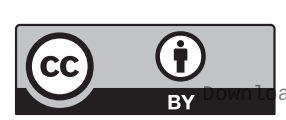

This work is licensed under a Creative Commons Attribution 4.0 International License.

ded from Bioscientifica.com at 04/26/2023 12:53:26PM 